\title{
Nuclear RFLP variation in Eucalyptus camaldulensis Dehnh. from northern Australia
}

\author{
PA Butcher ${ }^{1}$, A Otero ${ }^{1,2}$, MW McDonald ${ }^{1}$ and GF Moran ${ }^{1}$ \\ ${ }^{1} /$ CSIRO Forestry and Forest Products, PO Box E4008, Kingston, ACT 2604, Australia
}

\begin{abstract}
Eucalyptus camaldulensis Dehnh. is the most widely planted eucalypt in the tropics. Natural populations are riparian and sampling strategies for breeding programmes have assumed that gene flow among drainage basins is limited. RFLP variation, within and among 31 populations from river systems across northern Australia, was analysed to test this hypothesis. To allow comparisons within and between river systems, trees were sampled from up to three populations per river system. Allele frequencies were correlated with longitude for more than half the 33 RFLP loci surveyed. Genetic identity was greatest between populations in closest geographic proximity, irrespective of river system, suggest-
\end{abstract}

ing that sampling strategies for breeding programmes should be based on geographic distance rather than river system. The level of genetic variation was similar throughout the geographic range examined (mean $H_{\mathrm{E}}=0.49$ ). However, there was evidence of a barrier to gene flow between populations in the east and west of the species range. The RFLP data support morphological evidence of hybridisation between E. camaldulensis and E. tereticornis Sm. in several populations in northeast Queensland and the genetic divergence of E. camaldulensis subsp. simulata Brooker and Kleinig.

Heredity (2002) 88, 402-412. DOI: 10.1038/sj/hdy/6800074

Keywords: Eucalyptus camaldulensis; RFLPs; genetic diversity; geographic variation; cline; tree breeding

\section{Introduction}

Eucalyptus camaldulensis Dehnh. has the largest geographical range of any eucalypt, occurring over more than 5 million $\mathrm{km}^{2}$ of mainland Australia. However, it occupies a relatively narrow ecological niche, being confined mainly to watercourses. Climatic parameters vary substantially over its geographic range, for example, mean annual rainfall is mostly between 250 and $600 \mathrm{~mm}$, with some areas receiving up to $1600 \mathrm{~mm}$. In addition to being the most widely distributed eucalypt, it has high levels of phenotypic variation (Eldridge et al, 1993). Clinal variation has been reported in morphological and adaptive traits (Grunwald and Karschon, 1983); for example, water-use strategies of tropical populations differ according to climatic variables of their place of origin (Gibson et al, 1995). The broad climatic tolerances of the species have contributed to it becoming one of the most widely planted eucalypts. Southern provenances are suited to Mediterranean climates and northern provenances to tropical environments (reviewed in Eldridge et al, 1993). Of relevance to breeding programmes is whether the patterns of genetic diversity reflect variation in climatic and environmental parameters.

A sampling strategy of selecting populations from different drainage systems within broad climatic zones has

Correspondence: PA Butcher, CSIRO Forestry and Forest Products, PO Box E4008, Kingston, ACT 2604, Australia.

E-mail:Penny.Butcher@csiro.au

${ }^{2}$ Present address: Instituto de Ecologa, UNAM, Apdo. Postal 27-3

Xangari, cp 58089. Morelia, Michoacan, Mexico

Received 15 May 2001; accepted 1 December 2001 been recommended for E. camaldulensis provenance trials and breeding programmes (Turnbull, 1973). This was based on the assumption that, because the species is largely confined to watercourses, opportunities for gene flow between populations in adjacent drainage systems were limited (Turnbull, 1973). A close relationship between morphological traits of seed sources of E. camaldulensis and major drainage basins supported this assumption (Grunwald and Karschon, 1983). The species differs from other eucalypts in having two seed coats (Brooker and Slee, 2000), possibly an adaptation for water-transport of seed (Boland et al, 1980). Seed shed in the tropics coincides with the wet season (Doran and Burgess, 1993) and as seed is light (c. 670 viable seeds/g; Boland et al, 1980) and buoyant, it could readily be dispersed by water. The potential for downstream seed dispersal raises questions of whether levels of genetic diversity increase in the direction of river flow; and whether genetic differences can be detected among populations on different river systems.

Gene flow and the patterns of genetic diversity will also be affected by variation in flowering times and the activity of pollinators. Eucalyptus camaldulensis has a mixed mating system with outcrossing rates ranging from $t=0.86$ at Lake Albacutya in southeast Australia to $t=0.96$ in populations from northeast Queensland (McDonald et al, 1996). Trees produce masses of bisexual flowers that are generally pollinated by insects. Birds (Franklin and Noske, 2000) and fruit bats may play an important role in long distance pollen dispersal in northern Australia (Richards, 1995). Flowering can occur over an extended period within populations but follows a latitudinal cline among populations. Peak flowering occurs 
in July in populations from northeast Queensland, October to November in tropical Northern Territory and Western Australia, and December in southeastern populations. Flowering has been reported to be more heterogeneous in populations across central and Western Australia than on river systems flowing into the Gulf of Carpentaria (Banks, 1990). Whether differences in flowering have led to the genetic divergence of populations in different regions remains unknown.

The patterns of variation in E. camaldulensis may also be influenced by hybridisation. Natural hybrids have been recorded in northern Australia with E. bigalerita (Pryor and Byrne, 1969) and E. alba (Turnbull, 1973), and hybrids with E. tereticornis are common in eastern Australia where the species distributions overlap (Doran and Burgess, 1993). When closely related eucalypt species hybridise, vigorous fertile populations are often produced (Brooker and Kleinig, 1994). Evidence of hybridisation has been reported in populations of E. camaldulensis from the Petford region in Queensland, based on the shape of the operculum and the presence of individuals producing black seeds with a single seed coat (typical of E. tereticornis) (Doran and Burgess, 1993; Brooker and Kleinig, 1994). The Petford population has become one of the most important in E. camaldulensis breeding programmes in the tropics because of its fast growth rate (Doran and Burgess, 1993). The recently described subsp. simulata Brooker and Kleinig has morphological characters of E. camaldulensis and E. tereticornis (Brooker and Kleinig, 1994). Of interest is whether genetic differences can be detected between subsp. simulata, Petford and other populations of E. camaldulensis.

In this study the patterns of distribution of genetic diversity within and between populations of E. camaldulensis sens. lat. from river systems across northern Australia were examined. Patterns were explored in relation to geographic and climatic variables. In addition, genetic differences between E. camaldulensis var. obtusa (including Petford) and subsp. simulata were analysed for evidence of hybridisation with E. tereticornis.

\section{Materials and methods}

The study taxa

A number of infraspecific taxa have been documented for E. camaldulensis (Blakely, 1965; Pryor and Byrne, 1969; Brooker and Kleinig, 1994) but the boundaries between these taxa remain poorly resolved. Based on Brooker and Kleinig (1994), most populations in this study are putatively ascribed to E. camaldulensis var. obtusa Blakely. This variant has a mainly tropical occurrence and is widespread throughout much of inland and northern Australia. Three populations of E. camaldulensis subsp. simulata Brooker and Kleinig were also sampled in northeast Queensland. This taxon shares a number of characters with var. obtusa and E. tereticornis Sm. as it occupies a riparian habitat, has brown, double-coated seeds and juvenile foliage typical of var. obtusa and the tall, straight habit and long, horn-shaped operculum typical of E. tereticornis (Brooker and Kleinig, 1994). The geographic range of subsp. simulata is poorly known owing to the need to determine both seed coat anatomy and bud shape. Current knowledge suggests it is confined to the upper reaches of the Laura, Normanby, Palmer, Mitchell and Walsh Rivers in northeast Queensland.

\section{Sampling strategy}

Leaf samples were collected from a minimum of 10 mature individuals in each of 31 populations of E. camaldulensis, representing the major river systems in northern Australia (Figure 1). Location details and climatic parameters for these populations are listed in Table 1. All populations were from river systems flowing into the sea (exoreic drainage) with the exception of the Lander (30) and Rudall River (31) (Figure 1) which have endoreic drainage (internal drainage by rivers which do not reach the sea). All trees sampled were at least $100 \mathrm{~m}$ apart and were permanently tagged. Voucher specimens were lodged with the Australian National Herbarium, Canberra. Leaves were also sampled from eight E. tereticornis seedlings grown from two bulked seedlots for use as an outgroup in phylogenetic analyses.

\section{Probe selection and RFLP procedures}

DNA was extracted from leaves following Byrne et al, (1993). The quality of DNA extracted from several individuals was inadequate for RFLP analysis, hence only nine individuals were analysed from populations 8-10 and eight individuals from population 11. To select probe-enzyme combinations DNA from one tree in each of 13 E. camaldulensis populations was digested with Eco32I, BglII, DraI and HindIII and transferred to nylon membranes by capillary blotting in $0.4 \mathrm{M} \mathrm{NaOH}$ overnight. Membranes were hybridised with 40 RFLP probes which had previously been used to assess genetic variation in E. nitens (Byrne et al, 1998). Thirty-three probeenzyme combinations were selected which produced a clear hybridisation pattern consistent with alleles at a single locus; 17 probes were from a E. nitens genomic library (g059, g067, g086, g095, g099, g121, g142, g154, g174, g183, g195, g233, g243, g250, g256, g261, g409) and 16 probes from a E. globulus cDNA library (c030, c087, c092, c113, c115, c116, c135, c136, c137, c170, c238, c299, c333, c395, c411, c451). Thirty-one of the probes have been mapped in either E. nitens (Byrne et al, 1995) or E. globulus (Thamarus et al, 2001) and are therefore known to segregate in Mendelian fashion and span the eucalypt genome.

DNA samples from each population, digested with either Eco32I, BglII or HindIII, were subdivided between two gels and the ordering of populations randomized to maximise comparisons of alleles between populations and membranes. Probes were prepared by PCR amplification of inserts and labelled with ${ }^{32} \mathrm{P}$-dCTP using the random priming method (Feinberg and Vogelstein, 1983). Hybridisation and autoradiography followed Byrne et al. (1993) except that post-hybridisation washes were in $2 \times$ SSC, $0.1 \%$ SDS.

\section{Data analysis}

Alleles were scored at each locus and numbered according to increasing fragment size. Allele frequencies were calculated for each population using the programme FSTAT Version 2.9.1 (Goudet, 2000) and used to estimate the proportion of polymorphic loci $(P)$, allelic richness (average number of alleles per locus, $A_{\mathrm{R}}$ ), the number of alleles found in only one population (private alleles, $p(1)$ ), observed heterozygosity $\left(H_{\mathrm{O}}\right)$ and expected heterozygosity $\left(H_{\mathrm{E}}\right)$. The likelihood that observed genotype frequencies were in Hardy-Weinberg equilibrium was assessed using exact tests for each locus in each population (Weir, 1996). To identify geographic trends in gene 


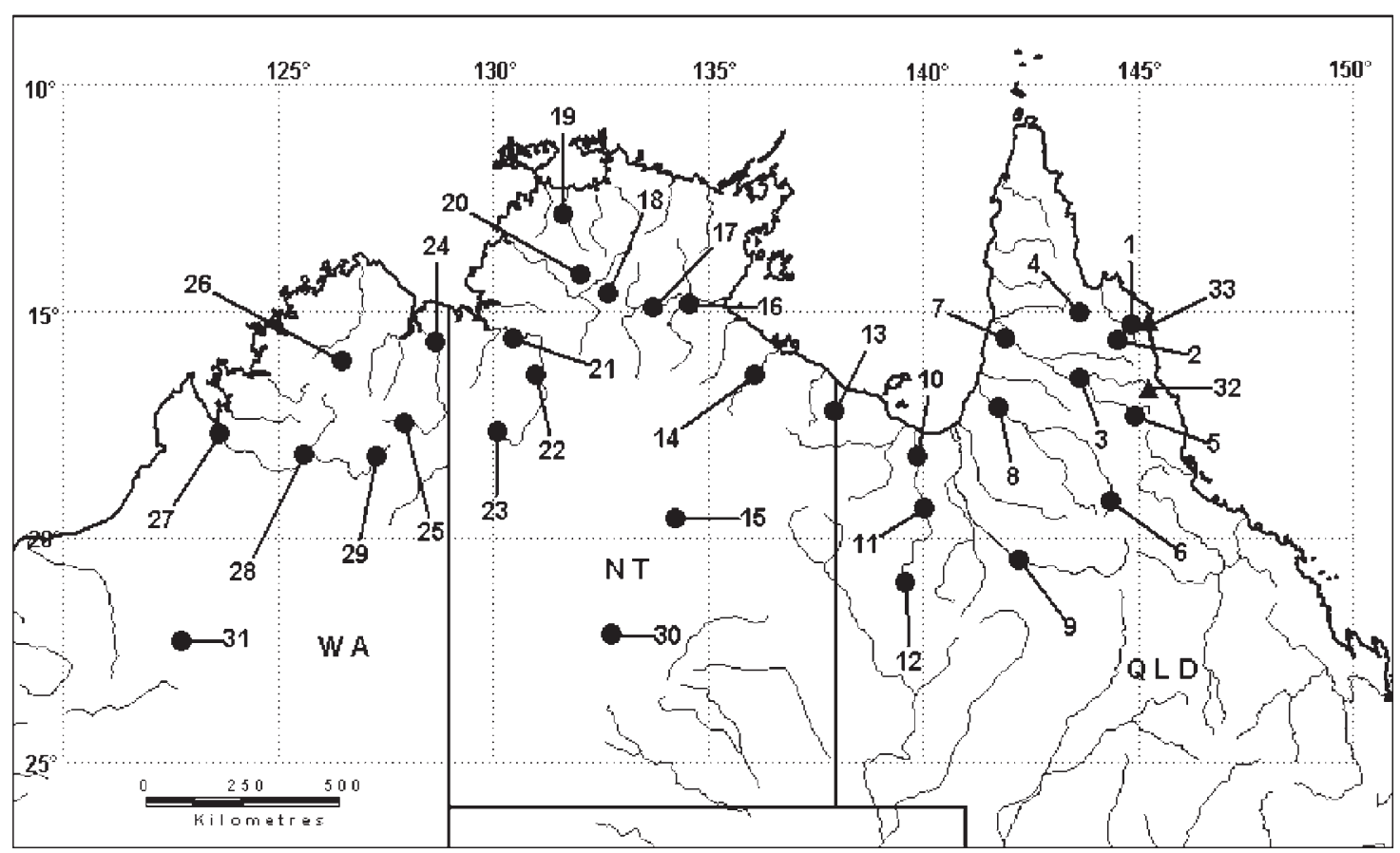

Figure 1 Location of sampled populations of Eucalyptus camaldulensis var. obtusa, E. camaldulensis subsp. simulata and E. tereticornis in Queensland (Qld), Northern Territory (NT) and Western Australia (WA). Numbers refer to population numbers in Table 1. Circles denote E. camaldulensis populations and triangles E. tereticornis.

diversity statistics $\left(A_{\mathrm{R}}, H_{\mathrm{E}}, H_{\mathrm{O}}\right)$ the proportion of variation explained by geographic parameters was estimated by linear regression. Associations between the frequency of the two most common alleles at each locus and geographic/climatic variables (latitude, longitude, altitude, mean annual rainfall and mean annual temperature) were tested using Pearson's correlation coefficients.

Inbreeding coefficients $(f)$ were estimated for each population using the programme GDA Version 1.0 (d13) (Lewis and Zaykin, 1999) based on formulae in Weir (1996). In addition, the total inbreeding coefficient $(F)$, coancestry coefficient $(\theta)$ and $(f)$ were calculated for geographic regions and over all populations. Confidence intervals (95\%) for $f, F$, and $\theta$ were estimated by bootstrapping over loci 1000 times.

Several methods were used to examine the patterns of distribution of genetic variation among populations. Homogeneity of allele frequencies among populations was tested by likelihood ratio tests using the programme POPGENE version 1.31 (Yeh and Boyle, 1999). To determine whether differences between populations within river systems were statistically significant, pairwise differences in $\theta$ among populations were also estimated, randomizing genotypes within samples, as described by Goudet (2000).

Geographic patterns in the data were investigated using principal component analysis (PCA) to reduce the dimensionality of the allele frequency data, using a variance-covariance matrix. Product moment correlation coefficients were calculated between the principal component scores and geographic/climatic variables using the PRINCOM and CORR procedures of the SAS statistical package (SAS Institute Inc, 1989).

Based on results from the PCA, populations were div- ided into two geographic regions (east and west) to examine the distribution of genetic variation within and among regions. Genetic diversity was calculated for each region and genetic differentiation between regions estimated using co-ancestry coefficients (Weir, 1996). The proportion of variation between populations that was attributable to the difference between regions was then estimated using the methods of Nei (1973).

Nei's (1972) genetic distances between populations $\left(D_{\mathrm{n}}\right)$ and standard errors were calculated using the programme GD (Ritland, 1989); genetic distances were then used to construct a UPGMA phenogram. Phylogenetic relationships were also investigated using maximum likelihood and the PHYLIP package (Felsenstein, 1993). Multiple datasets (500) were generated from the allele frequency data by bootstrapping (SEQBOOT programme), a phylogeny determined for each dataset by restricted maximum likelihood (CONTML programme) and a consensus tree generated using E. tereticornis as an outgroup (CONSENSE programme).

The correlation between Nei's (1978) unbiased genetic distance and geographic distance ( $\log _{10}$ transformed) was assessed by Mantel test (1000 iterations) using the computer programme of Liedloff et al (1997).

\section{Results}

Levels of genetic diversity

Polymorphisms were detected in one or more populations with all RFLP probes. A total of 413 alleles were scored at 33 loci. The number of alleles detected in each population ranged from 101 in Mary River (pop. 19) to 147 in Petford (pop. 5). The differences among populations were largely due to differences in the frequency 
Table 1 Location and climatic details of sampled populations of Eucalyptus camaldulensis and E. tereticornis

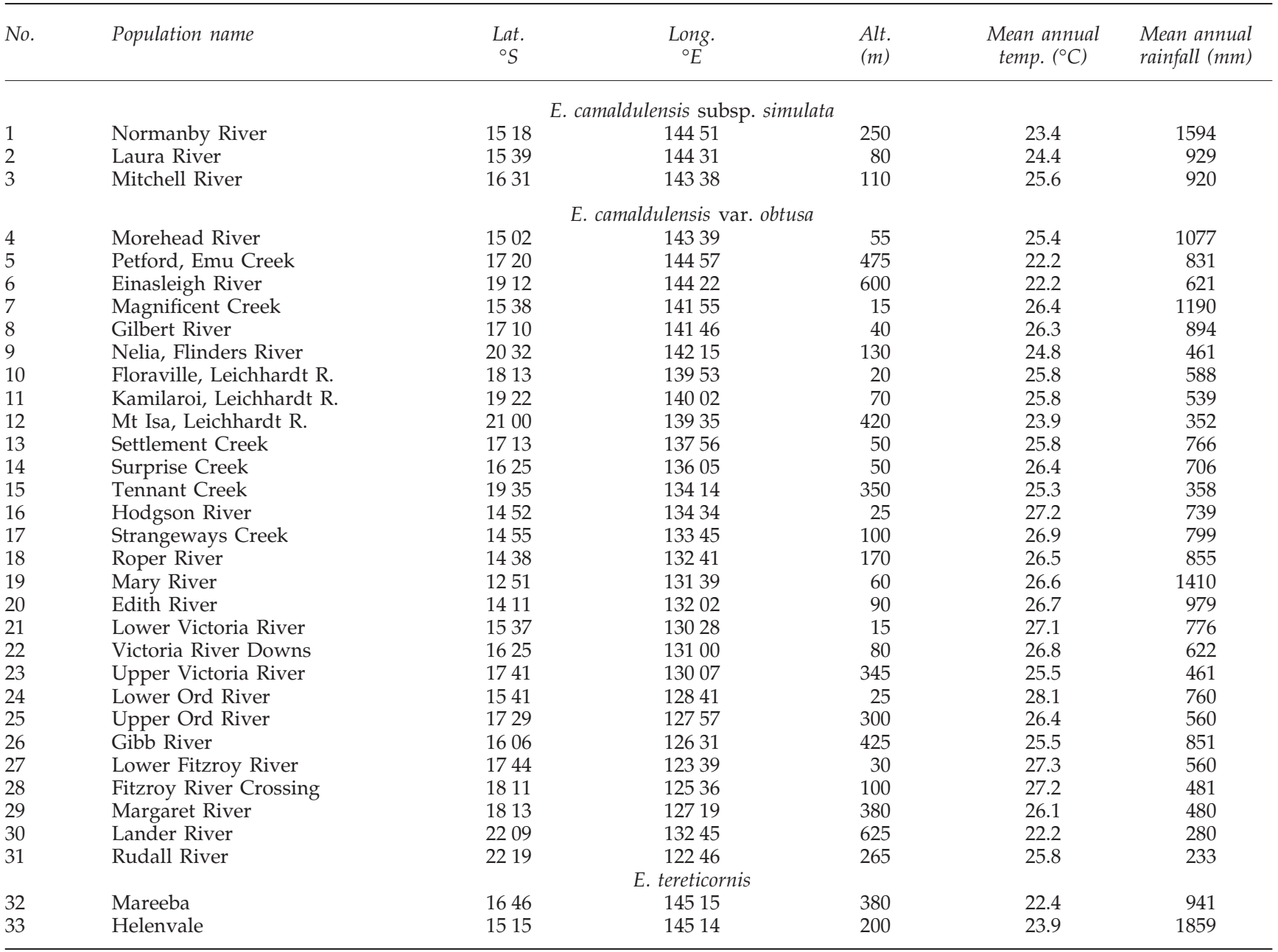

of rare alleles (frequency $<0.1$ ), with populations at the northern limit of the species distribution $(4,18,19,20,26)$ having fewer rare alleles. The overall distribution of alleles was skewed towards alleles of low frequency compared with the U-shaped distributions reported for isozymes (for $H_{\mathrm{E}}<0.3$ ) (Chakraborty et al, 1980). It was, however, consistent with an increase in the numbers of rare alleles with increasing heterozygosity predicted in the infinite alleles model with varying mutation rates (Chakraborty et al, 1980). Seventy-five percent of alleles occurred at frequencies of less than 5\% over all populations and $30 \%$ of alleles were unique to a population. A similar distribution of alleles at RFLP loci was reported for the E. kochii group (Byrne, 1999).

The highest estimates of genetic variation $\left(P, A_{\mathrm{R}}, H_{\mathrm{E}}\right.$ and $H_{\mathrm{O}}$ ) were for the Petford population (Table 2) while the lowest genetic diversity was in the northern-most population of Mary River. Eighteen percent of variation in $A_{\mathrm{R}}$ was explained by latitude; $8 \%$ of variation in $H_{\mathrm{O}}$ was explained by longitude. The level of diversity was similar in eastern populations (mean $H_{\mathrm{E}}=0.52$ ) and western populations (mean $H_{\mathrm{E}}=0.51$ ), however more private alleles were detected in the east (73 in 12 populations) than in the west (48 in 19 populations).

There was little evidence of departure from HardyWeinberg equilibrium. Thirty-four out of 1023 exact tests for Hardy-Weinberg equilibrium were significant $(\mathrm{Pr} \leq$ 0.05), fewer than the 5\% expected due to chance alone. At the higher exclusion level $(\operatorname{Pr} \leq 0.01)$ only three tests, for different loci in different populations, were significant (c30 pop. 22; c411 pop. 24; and c451 pop. 29). There was no evidence of inbreeding $(f=0.02$; Table 3$)$, indicating populations are in equilibrium and have not been subject to pressures that would adversely affect mating.

\section{Distribution of genetic diversity}

The majority of variation (92\%) occurred within populations. However, confidence intervals for $\theta$ (Table 3 ) indicate significant divergence among populations. Of the $7.8 \%$ of genetic diversity attributable to differences among populations, two-thirds was due to the difference between the eastern and western regions. The greatest differences, determined from pairwise comparisons of $\theta$, were between the subsp. simulata populations $(1,2)$ and Edith River (20). There were significant pairwise differences among populations on five of the seven river systems; only differences along the Leichhardt (populations $9,10,11)$ and Ord Rivers $(24,25)$ were not significant.

To examine these differences in more detail homogeneity tests for differences in allele frequencies among the E. camaldulensis populations were carried out. There were significant differences $(P \leq 0.05)$ at nine loci $(c 113$; 
Table 2 Estimates of genetic variation parameters in Eucalyptus camaldulensis and E. tereticornis populations based on allele frequencies at 33 RFLP loci

\begin{tabular}{|c|c|c|c|c|c|c|c|c|}
\hline No. & Population name & $n$ & $P$ & $A_{\mathrm{R}}$ & $p(1)$ & $H_{\mathrm{E}}$ & $H_{\mathrm{O}}$ & $f$ \\
\hline \multicolumn{9}{|c|}{ E. camaldulensis subsp. simulata } \\
\hline 1 & Normanby River & 10 & 0.94 & 3.76 & 1 & 0.46 & 0.47 & -0.029 \\
\hline 2 & Laura River & 10 & 0.94 & 3.79 & 2 & 0.47 & 0.46 & 0.022 \\
\hline 3 & Mitchell River & 10 & 0.97 & 3.91 & 7 & 0.49 & 0.46 & 0.057 \\
\hline \multicolumn{9}{|c|}{ E. camaldulensis var. obtusa } \\
\hline 4 & Morehead River & 10 & 0.94 & 3.24 & 2 & 0.48 & 0.51 & -0.069 \\
\hline 5 & Petford, Emu Creek & 10 & 1.00 & 4.45 & $\overline{9}$ & 0.56 & 0.56 & -0.012 \\
\hline 6 & Einasleigh River & 13 & 0.97 & 4.15 & 7 & 0.50 & 0.49 & 0.035 \\
\hline 7 & Magnificent Creek & 10 & 0.91 & 4.12 & 7 & 0.50 & 0.53 & -0.055 \\
\hline 8 & Gilbert River & 9 & 0.94 & 4.15 & 8 & 0.50 & 0.51 & -0.033 \\
\hline 9 & Nelia, Flinders River & 9 & 0.97 & 3.79 & 0 & 0.48 & 0.47 & 0.028 \\
\hline 10 & Floraville, Leichhardt R. & 9 & 0.94 & 4.00 & 6 & 0.49 & 0.47 & 0.034 \\
\hline 11 & Kamilaroi, Leichhardt R. & 8 & 0.91 & 3.73 & 3 & 0.45 & 0.44 & 0.013 \\
\hline 12 & Mt Isa, Leichhardt R. & 10 & 0.94 & 3.88 & 3 & 0.49 & 0.49 & 0.014 \\
\hline 13 & Settlement Creek & 10 & 0.91 & 3.97 & 3 & 0.51 & 0.49 & 0.049 \\
\hline 14 & Surprise Creek & 10 & 0.94 & 3.97 & 4 & 0.53 & 0.50 & 0.047 \\
\hline 15 & Tennant Creek & 10 & 0.97 & 4.39 & 1 & 0.52 & 0.48 & 0.090 \\
\hline 16 & Hodgson River & 10 & 0.97 & 4.09 & 4 & 0.51 & 0.49 & 0.034 \\
\hline 17 & Strangeways Creek & 10 & 0.91 & 3.70 & 3 & 0.50 & 0.46 & 0.081 \\
\hline 18 & Roper River & 10 & 0.94 & 3.24 & 2 & 0.47 & 0.46 & 0.024 \\
\hline 19 & Mary River & 10 & 0.91 & 3.06 & 0 & 0.43 & 0.43 & -0.010 \\
\hline 20 & Edith River & 10 & 0.88 & 3.39 & 3 & 0.46 & 0.45 & 0.017 \\
\hline 21 & Lower Victoria River & 10 & 0.94 & 3.61 & 4 & 0.46 & 0.45 & 0.027 \\
\hline 22 & Victoria River Downs & 10 & 0.91 & 3.88 & 1 & 0.49 & 0.48 & 0.012 \\
\hline 23 & Upper Victoria River & 10 & 0.97 & 3.76 & 2 & 0.50 & 0.54 & -0.087 \\
\hline 24 & Lower Ord River & 10 & 0.94 & 3.97 & 3 & 0.48 & 0.45 & 0.064 \\
\hline 25 & Upper Ord River & 10 & 0.97 & 4.03 & 4 & 0.48 & 0.45 & 0.067 \\
\hline 26 & Gibb River & 10 & 0.97 & 3.64 & 2 & 0.51 & 0.50 & 0.013 \\
\hline 27 & Lower Fitzroy River & 10 & 0.94 & 4.27 & 1 & 0.52 & 0.49 & 0.063 \\
\hline 28 & Fitzroy River Crossing & 10 & 0.91 & 3.70 & 4 & 0.48 & 0.49 & -0.025 \\
\hline 29 & Margaret River & 10 & 0.94 & 3.76 & 1 & 0.46 & 0.45 & 0.020 \\
\hline 30 & Lander River & 10 & 0.94 & 4.06 & 1 & 0.49 & 0.49 & 0.012 \\
\hline \multirow[t]{3}{*}{31} & Rudall River & 10 & 0.88 & 3.79 & 5 & 0.44 & 0.42 & 0.056 \\
\hline & Mean (s.e.) & & $0.94(0.03)$ & $3.85(0.06)$ & & $0.49(0.01)$ & $0.48(0.01)$ & \\
\hline & \multicolumn{8}{|c|}{ E. tereticornis } \\
\hline 32 & Mareeba & 3 & 0.76 & 2.24 & 1 & 0.45 & 0.48 & -0.097 \\
\hline 33 & Helenvale & 5 & 0.85 & 2.73 & 2 & 0.51 & 0.53 & -0.041 \\
\hline
\end{tabular}

$n=$ sample size; $P=$ proportion of polymorphic loci ( 0.99 criterion); $A_{R}=$ mean number of alleles per locus; $p(1)=$ number of private alleles; $H_{\mathrm{E}}=$ expected heterozygosity; $H_{\mathrm{O}}=$ observed heterozygosity; $f=$ inbreeding coefficient.

Table 3 Mean and 95\% confidence intervals (in brackets) for estimates of the degree of inbreeding within populations of Eucalyptus camaldulensis $(f)$; the overall inbreeding coefficient $(F)$ and the coancestry coefficient $(\theta)$

\begin{tabular}{|c|c|c|c|}
\hline & $f$ & $F$ & $\theta$ \\
\hline Eastern region & 0.001 & 0.066 & 0.065 \\
\hline (Populations 1-12) & $(-0.026,0.027)$ & $(0.034,0.100)$ & $(0.049,0.084)$ \\
\hline Western region & 0.029 & 0.073 & 0.044 \\
\hline (Populations 13-29) & $(0.010,0.049)$ & $(0.052,0.093)$ & $(0.036,0.053)$ \\
\hline Overall & 0.019 & 0.095 & 0.078 \\
\hline (Populations 1-31) & $(-0.002,0.038)$ & $(0.068,0.123)$ & $(0.060,0.100)$ \\
\hline
\end{tabular}

g86; g99; c137; g250; c451; c299; g256; g121). These included differences in common alleles at locus c113 between populations 1-12 in Queensland (defined as the eastern region) and populations 13-29 in Northern Territory and Western Australia (western region) (Table 4). Populations 30 and 31, which differ from all other populations in occurring on endoreic drainage systems, had the same common allele at this locus as populations in the eastern region. There were also differences in common alleles at loci g86 and g99 in the Morehead (4), Normanby (1), Laura (2), Petford (5) and Mitchell River (3) populations; a different common allele at locus c137 in Normanby (1) and Laura (2); and at locus c451 in Morehead (4). Mt Isa (12) and Floraville (10) on the Leichhardt River had different allelic profiles from other populations for locus g121 (Table 4). The pattern of allele frequencies at loci g250, g256 and g299 was more complex, however, all differences followed geographic trends. For loci c113, g86 and g99, the most common allele in the Queensland populations, noted above, was the same as in E. tereticornis. These data are consistent with morphological evidence of hybridisation between the two taxa.

Seventy-three alleles were restricted to the eastern populations, 71 of which occurred at a frequency less than $5 \%$ and 51 of which were unique to a population. Eighty-six alleles were detected only in the western populations, all at a frequency of less than 5\% and 50 of which were unique to a population. While there were differences in common alleles between E. tereticornis and E. camaldulensis at six loci (c87, c135, g142, g183, g299 and c395), only three alleles were detected in E. tereticornis 
Table 4 Freequencies of the most common alleles at six RFLP loci (allele number in brackets) for populations of Eucalyptus camaldulensis and E. tereticornis

\begin{tabular}{|c|c|c|c|c|c|c|c|c|c|c|c|c|c|}
\hline No. & Population name & $\begin{array}{c}c 113 \\
(7)\end{array}$ & $\begin{array}{l}c 113 \\
(12)\end{array}$ & $\begin{array}{c}g 86 \\
(6)\end{array}$ & $\begin{array}{l}g 86 \\
(12)\end{array}$ & $\begin{array}{l}899 \\
\text { (3) }\end{array}$ & $\begin{array}{l}899 \\
(5)\end{array}$ & $\begin{array}{c}c 137 \\
(5)\end{array}$ & $\begin{array}{c}c 137 \\
(8)\end{array}$ & $\begin{array}{c}c 451 \\
(1)\end{array}$ & $\begin{array}{c}c 451 \\
(7)\end{array}$ & $\begin{array}{c}g 121 \\
\text { (3) }\end{array}$ & $\begin{array}{c}g 121 \\
(4)\end{array}$ \\
\hline \multicolumn{14}{|c|}{ E. camaldulensis subsp. simulata } \\
\hline 1 & Normanby River & 0.95 & - & 0.20 & 0.55 & 0.05 & 0.95 & 0.25 & 0.20 & 0.05 & 0.60 & - & 0.85 \\
\hline 2 & Laura River & 0.95 & - & 0.30 & 0.50 & 0.30 & 0.70 & 0.65 & 0.15 & 0.05 & 0.40 & - & 0.75 \\
\hline 3 & Mitchell River & 0.94 & 0.06 & 0.35 & 0.40 & 0.45 & 0.50 & 0.20 & 0.40 & 0.10 & 0.50 & - & 0.80 \\
\hline \multicolumn{14}{|c|}{ E. camaldulensis var. obtusa } \\
\hline 4 & Morehead River & 0.60 & 0.25 & 0.05 & 0.75 & 0.30 & 0.65 & 0.22 & 0.56 & 0.35 & 0.15 & - & 0.80 \\
\hline 5 & Petford, Emu Creek & 0.80 & 0.15 & 0.35 & 0.45 & 0.50 & 0.50 & 0.10 & 0.25 & 0.17 & 0.39 & 0.05 & 0.90 \\
\hline 6 & Einasleigh River & 1.00 & - & 0.50 & 0.39 & 0.54 & 0.42 & 0.27 & 0.39 & 0.06 & 0.56 & - & 0.96 \\
\hline 7 & Magnificent Creek & 0.65 & 0.20 & 0.40 & 0.30 & 0.75 & 0.25 & 0.15 & 0.40 & 0.05 & 0.30 & 0.05 & 0.75 \\
\hline 8 & Gilbert River & 0.67 & 0.28 & 0.56 & 0.11 & 0.78 & 0.22 & 0.11 & 0.22 & - & 0.56 & 0.06 & 0.78 \\
\hline 9 & Nelia, Flinders River & 0.89 & 0.06 & 0.56 & 0.22 & 0.67 & 0.33 & 0.17 & 0.28 & 0.06 & 0.67 & - & 0.94 \\
\hline 10 & Floraville & 0.72 & 0.11 & 0.83 & - & 0.83 & 0.11 & - & 0.50 & 0.06 & 0.44 & 0.44 & 0.50 \\
\hline 11 & Kamilaroi & 0.56 & 0.38 & 0.75 & 0.06 & 1.00 & - & 0.50 & 0.06 & - & 0.50 & - & 1.00 \\
\hline 12 & Mt Isa, Leichhardt R. & 0.95 & - & 0.89 & 0.11 & 0.85 & 0.10 & - & 0.42 & _- & 0.56 & 0.38 & 0.63 \\
\hline 13 & Settlement Creek & 0.15 & 0.70 & 0.95 & - & 0.80 & 0.20 & 0.20 & 0.40 & - & 0.20 & - & 0.85 \\
\hline 14 & Surprise Creek & 0.15 & 0.85 & 0.85 & - & 0.90 & 0.10 & - & 0.40 & - & 0.40 & - & 0.95 \\
\hline 15 & Tennant Creek & 0.40 & 0.55 & 0.95 & - & 0.89 & 0.11 & 0.06 & 0.33 & - & 0.28 & - & 0.90 \\
\hline 16 & Hodgson River & 0.50 & 0.30 & 0.80 & 0.05 & 0.80 & 0.20 & 0.10 & 0.40 & - & 0.44 & 0.11 & 0.89 \\
\hline 17 & Strangeways Creek & 0.55 & 0.15 & 0.80 & - & 0.85 & 0.15 & 0.06 & 0.56 & 0.06 & 0.56 & - & 1.00 \\
\hline 18 & Roper River & 0.40 & 0.60 & 0.90 & - & 0.95 & 0.05 & 0.15 & 0.10 & 0.11 & 0.22 & - & 1.00 \\
\hline 19 & Mary River & 0.45 & 0.55 & 0.55 & - & 0.80 & 0.20 & - & 0.75 & - & 0.60 & - & 1.00 \\
\hline 20 & Edith River & 0.06 & 0.94 & 3.39 & - & 0.95 & 0.05 & 0.06 & 0.50 & - & 0.39 & 0.11 & 0.78 \\
\hline 21 & Lower Victoria & 0.25 & 0.50 & 3.61 & - & 0.95 & 0.05 & 0.05 & 0.60 & 0.05 & 0.35 & 0.05 & 0.90 \\
\hline 22 & Victoria River & 0.30 & 0.50 & 3.88 & - & 0.50 & 0.45 & 0.05 & 0.50 & 0.30 & 0.35 & 0.06 & 0.78 \\
\hline 23 & Upper Victoria & 0.44 & 0.44 & 3.76 & - & 0.75 & 0.25 & 0.10 & 0.30 & - & 0.35 & 0.10 & 0.85 \\
\hline 24 & Lower Ord River & 0.15 & 0.70 & 3.97 & - & 0.90 & 0.10 & 0.10 & 0.20 & 0.11 & 0.33 & - & 0.75 \\
\hline 25 & Upper Ord River & 0.10 & 0.60 & 4.03 & - & 0.85 & 0.10 & 0.25 & 0.40 & - & 0.20 & 0.06 & 0.88 \\
\hline 26 & Gibb River & 0.15 & 0.85 & 3.64 & _- & 0.80 & 0.20 & 0.15 & 0.30 & - & 0.25 & 0.11 & 0.78 \\
\hline 27 & Lower Fitzroy River & 0.39 & 0.50 & 4.27 & - & 1.00 & - & 0.20 & 0.40 & 0.05 & 0.50 & 0.10 & 0.85 \\
\hline 28 & Fitzroy River & 0.15 & 0.75 & 3.70 & 0.05 & 0.89 & 0.11 & - & 0.45 & 0.19 & 0.44 & - & 0.94 \\
\hline 29 & Margaret River & 0.22 & 0.78 & 3.76 & - & 0.70 & 0.25 & - & 0.22 & 0.06 & 0.50 & - & 0.93 \\
\hline 30 & Lander River & 0.60 & 0.25 & 4.06 & 0.10 & 0.75 & 0.20 & 0.25 & 0.50 & - & 0.45 & 0.17 & 0.78 \\
\hline 31 & Rudall River & 0.45 & 0.30 & 0.95 & - & 0.40 & 0.60 & 0.25 & 0.60 & 0.06 & 0.45 & - & 0.85 \\
\hline \multicolumn{14}{|c|}{ E. tereticornis } \\
\hline 32 & Mareeba & 0.83 & - & 0.33 & 0.67 & - & 0.67 & 0.50 & 0.50 & 0.05 & 0.50 & - & 1.00 \\
\hline 33 & Helenvale & 0.70 & - & 0.40 & 0.60 & - & 0.75 & - & 0.50 & 0.10 & 0.50 & 0.20 & 0.70 \\
\hline
\end{tabular}

and not in E. camaldulensis. These included the most common allele at g87 in E. tereticornis and rare alleles at g243 and c136. The low number of alleles specific to E. tereticornis in part reflects the small number of individuals sampled.

\section{Patterns of genetic variation}

Geographic trends were evident in the plot of principal component scores (Figure 2). Eastern populations had positive values on the pca-1 axis and western populations had negative values. The two populations on inland drainage systems (30 and 31) were positioned between the eastern and western regions. Western populations were also more tightly clustered than eastern populations. The first two principal components accounted for $21 \%$ and $10 \%$ of the variance respectively. Longitude $(r$ $=0.82 ; \operatorname{Pr} \leq 0.0001)$, mean annual rainfall $(r=0.38 ; \operatorname{Pr} \leq$ $0.038)$ and mean annual temperature $(r=-0.61 ; \operatorname{Pr} \leq$ 0.0003 ) were correlated with the first principal component; latitude $(r=0.46 ; \operatorname{Pr} \leq 0.0003)$ and mean annual rainfall ( $r=0.39 ; \operatorname{Pr} \leq 0.032)$ with the second principal component. There was no correlation with altitude.

The associations between allele frequencies and geographic variables were further demonstrated by signifi- cant correlations between the frequency of the most common allele at 15 of the 33 loci and longitude; four loci and latitude. There were also significant correlations (Pr $<0.05)$ with mean annual temperature at seven loci and mean annual rainfall at six loci. Correlations with altitude were significant at only one locus; two loci would be expected due to chance alone.

\section{Genetic distance}

Genetic differentiation between populations in the eastern and western regions was also evident in the UPGMA phenogram (Figure 3). The average genetic distance (Nei, 1972) between populations in the eastern region and western regions $\left(D_{n}=0.163\right.$, s.e. $\left.=0.039\right)$ was greater than the average distance between populations within these regions; $D_{\mathrm{n}}=0.119$, s.e. $=0.028$ for eastern populations and $D_{\mathrm{n}}=0.101$, s.e. $=0.023$ for western populations. Genetic distances among populations in the eastern region were also greater, on average, than between populations in the western region. This difference increased when the two populations $(30,31)$ on inland drainage systems were excluded from the western region (mean $D_{n}=0.096$, s.e. $=0.022$ ). Based on genetic distances, E. tereticornis was most similar to the subsp. simulata populations $(1,2$ and 


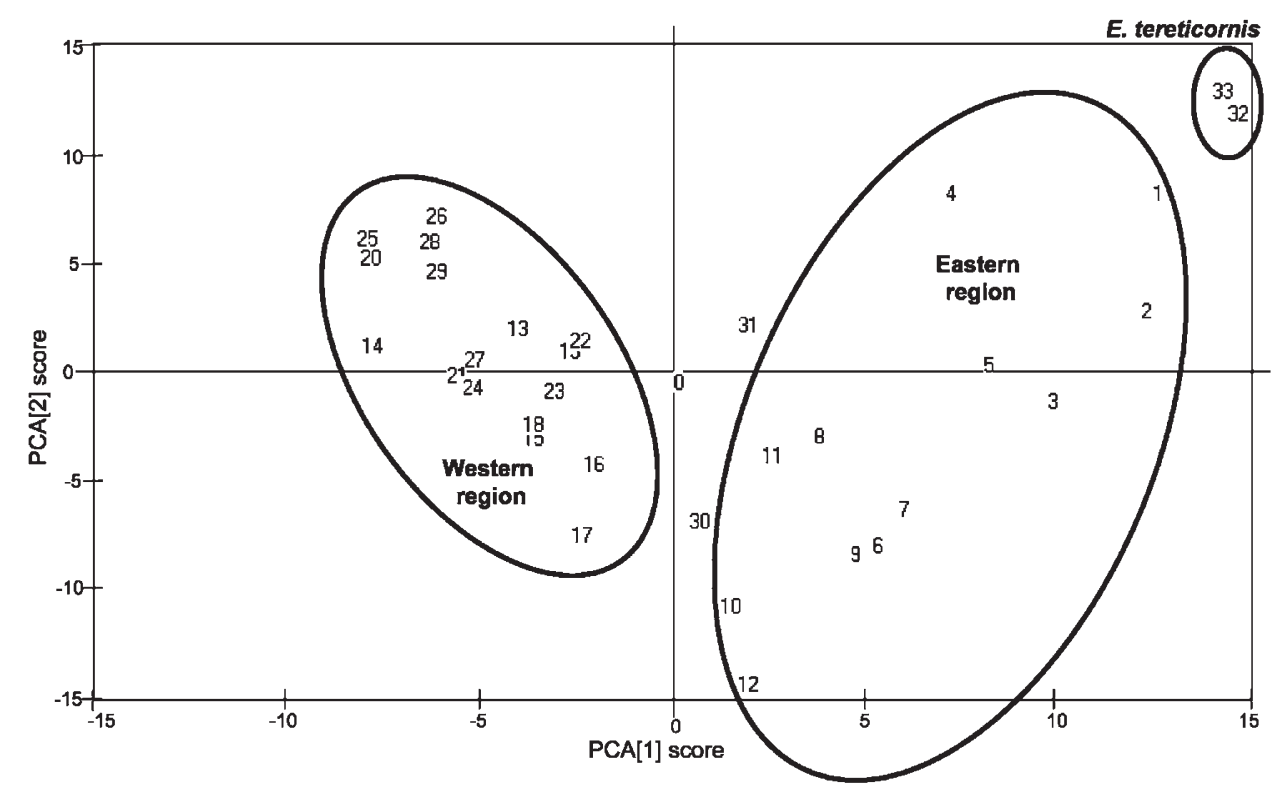

Figure 2 Plot of scores from a principal component analysis of allele frequencies from 31 populations of Eucalyptus camaldulensis and two populations of E. tereticornis.

3) (mean $D_{n}=0.144$, s.e. $=0.032$ ). Overall, the mean genetic distance between E. camaldulensis populations was 0.134 (s.e. $=0.032$ ).

The phylogenetic analysis, based on maximum likelihood, showed bootstrap support for a split between populations east and west of the Leichhardt River with western populations remaining unresolved (Figure 4). It was consistent with a decreasing influence of $E$. tereticornis from the subsp. simulata populations to Petford.

Genetic distance (Nei, 1978) was positively correlated with geographic distance (mantel coefficient $r=0.554, \mathrm{Pr}$ $\leq 0.001$ ). This is reflected in the dendrogram (Figure 3 ) where populations in closest geographic proximity cluster together. Populations on the same river systems often did not cluster into the same group. Genetic distances and geographic distances were also positively correlated within the eastern and western regions $(r=0.683$ and $r$ $=0.559$ respectively, $\operatorname{Pr} \leq 0.001$ ).

\section{Discussion}

\section{Genetic diversity}

The level of genetic diversity in populations of E. camaldulensis was high throughout the northern distribution of the species' geographic range. The northern-most population, Mary River (19), had the lowest genetic diversity $\left(H_{\mathrm{E}}\right.$ and $\left.A_{\mathrm{R}}\right)$ and no unique alleles, consistent with fewer opportunities for gene flow at the extremes of the species distribution. The association between allelic richness and latitude also suggests a general trend of reduced genetic diversity at the periphery of the species distribution. However, there was no evidence of increased inbreeding. Within river systems there was no consistent pattern of increasing genetic diversity from upstream to downstream populations which might be expected if waterborne transport of seed was important.

The Petford population (5), which had the highest genetic diversity, has consistently outperformed other seed sources in provenance trials throughout the seasonally dry tropics (Otegbeye, 1985; Midgley et al, 1989; Pinyopusarerk et al, 1996). A similar trend of high genetic diversity in populations with high growth rates has been reported in Casuarina cunninghamiana (Moran et al, 1989) and Acacia mangium (Butcher et al, 1996). While parallel rankings have been reported at the population level, data to support a similar trend at the individual tree level are lacking (eg, Aradhya and Phillips, 1995; Savolainen and Hedrick, 1995; Aravanopoulos, 2000).

At the species level, RFLP variation in E. camaldulensis $\left(H_{\mathrm{T}}=0.53\right)$ was similar to that reported for other eucalypts using the same genetic markers, for example, $E$. nitens $\left(H_{\mathrm{T}}=0.45\right)$ based on 40 RFLP loci (Byrne et al, 1998); E. kochii ssp. kochii $\left(H_{\mathrm{T}}=0.49\right)$, E. kochii ssp. plenissima $\left(H_{\mathrm{T}}\right.$ $=0.51)$ and $E$. horistes $\left(H_{\mathrm{T}}=0.49\right)$ based on 30 RFLP loci (Byrne, 1999); and E. sieberi $\left(H_{\mathrm{T}}=0.40\right)$ based on 10 RFLP loci (Glaubitz et al, 1999).

\section{Distribution of genetic diversity}

The correlation between geographic distance and genetic distance, together with results from the multivariate analyses, indicate that genetic similarity is associated with geographic proximity, irrespective of whether populations occur on the same river system. This suggests that pollen flow is more important than water-borne seed dispersal to gene flow in E. camaldulensis. If water-borne seed dispersal were important, levels of differentiation among populations from different river systems would be expected to be higher than among populations on the same river system. Instead, populations tend to be most similar to those in closest proximity (Figure 2). Similarly, genetic diversity might be expected to be greater in populations at lower altitudes that sample a larger proportion of the catchment. There was no evidence to support either scenario.

The geographic and climatic trends in allele frequencies are consistent with reports of clinal variation in morphometric and adaptive traits. Clinal trends in adaptive variation have been reported for $E$. camaldulensis 


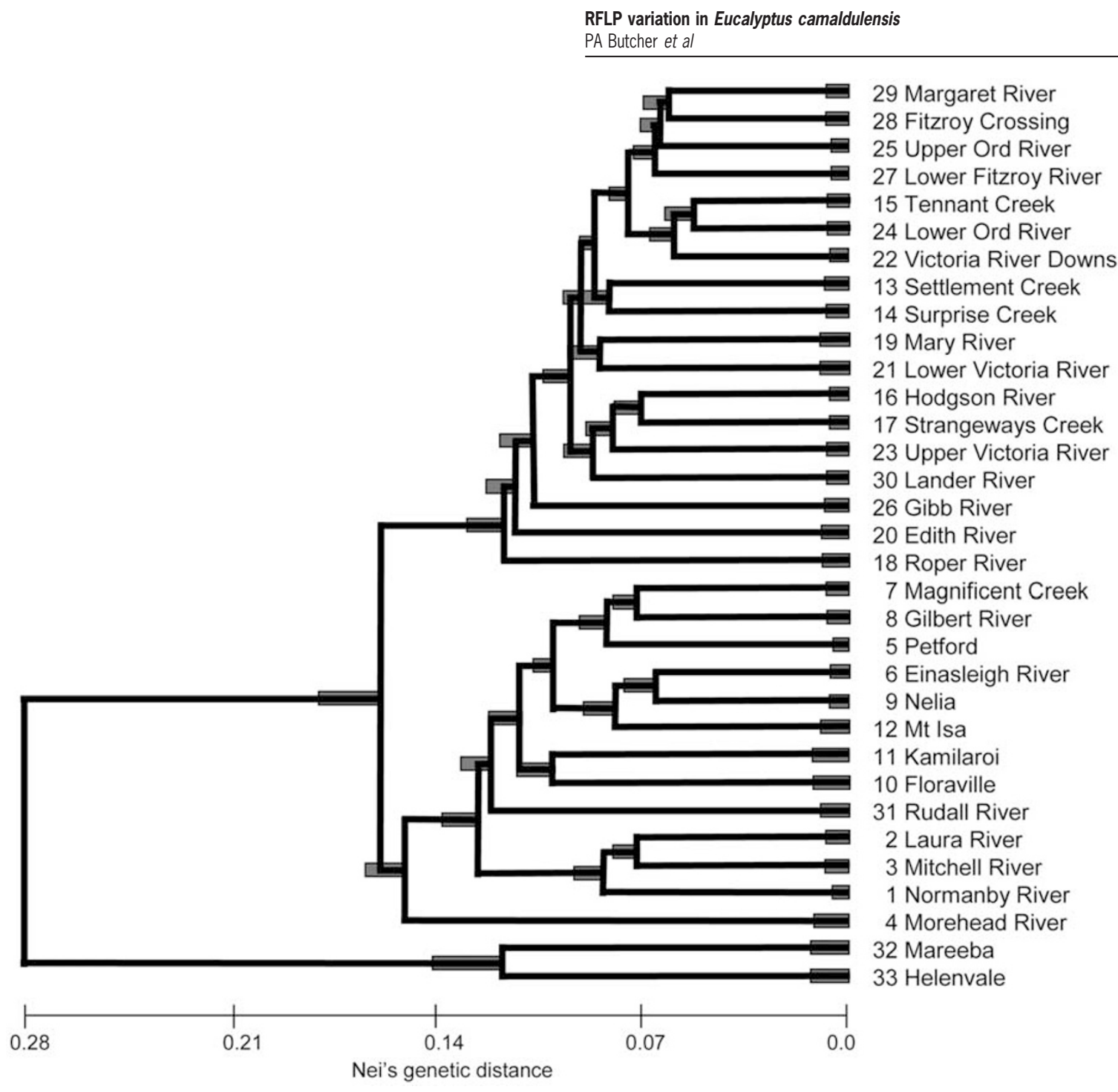

Figure 3 Cluster analysis of 31 populations of Eucalyptus camaldulensis and two populations of E. tereticornis based on Nei's genetic distance and the UPGMA algorithm. Clusters are significant if the standard error bar, depicted as a broad line, is less than half the branch length.

populations relating to tolerance to drought (Gibson et al, 1995) and frost (Grunwald and Karschon, 1977). Latitudinal and longitudinal clines in morphometric characters were also reported by Grunwald and Karschon (1983), based on data from 31 seed sources of tropical E. camaldulensis planted in provenance trials in Israel. Sclerophylly and epicuticular waxes increased with latitude while the presence of lignotubers decreased. Lignotubers increased with longitude and oil gland density decreased. Significant correlations with climatic parameters of the seed source were also reported. Oil gland density was positively correlated with mean maximum temperature while sclerophylly and epicuticular waxes were negatively correlated with rainfall.

Clines can be attributed either to adaptation to different environments, or to non-adaptive processes related to population structure and history, for example genetic drift, gene flow, or isolation by distance. Drift or historical processes should affect all loci equally while selection determining allele frequencies at a specific locus should have no affect on allele frequencies at unlinked loci (for neutral RFLP markers) (Cavalli-Sforza, 1966). The high number of RFLP loci $(15 / 33)$ for which the frequency of the most common allele was correlated with longitude indicates genetic drift or historical processes have influenced the patterns of variation. This is supported by the significant correlation between genetic distance and geographic distance, consistent with the isolation by distance model. The correlations between allele frequencies at several loci and climatic variables, together with evidence of different physiological responses to water stress among northern populations of E. camaldulensis which relate directly to climatic parameters (Gibson et al, 1995), indicate that selection has also influenced the patterns of variation.

Differentiation among eastern and western populations Affinities between the eastern-most populations of $E$. camaldulensis and E. tereticornis suggest that introgression of genes from E. tereticornis contributed to the differentiation between the western and eastern regions. This is also reflected in the higher level of differentiation among populations in the eastern region. The significant difference between populations to the east and west of the Leichhardt River in the phylogenetic analysis (Figure 4) may reflect the temporal shift in flowering between these 


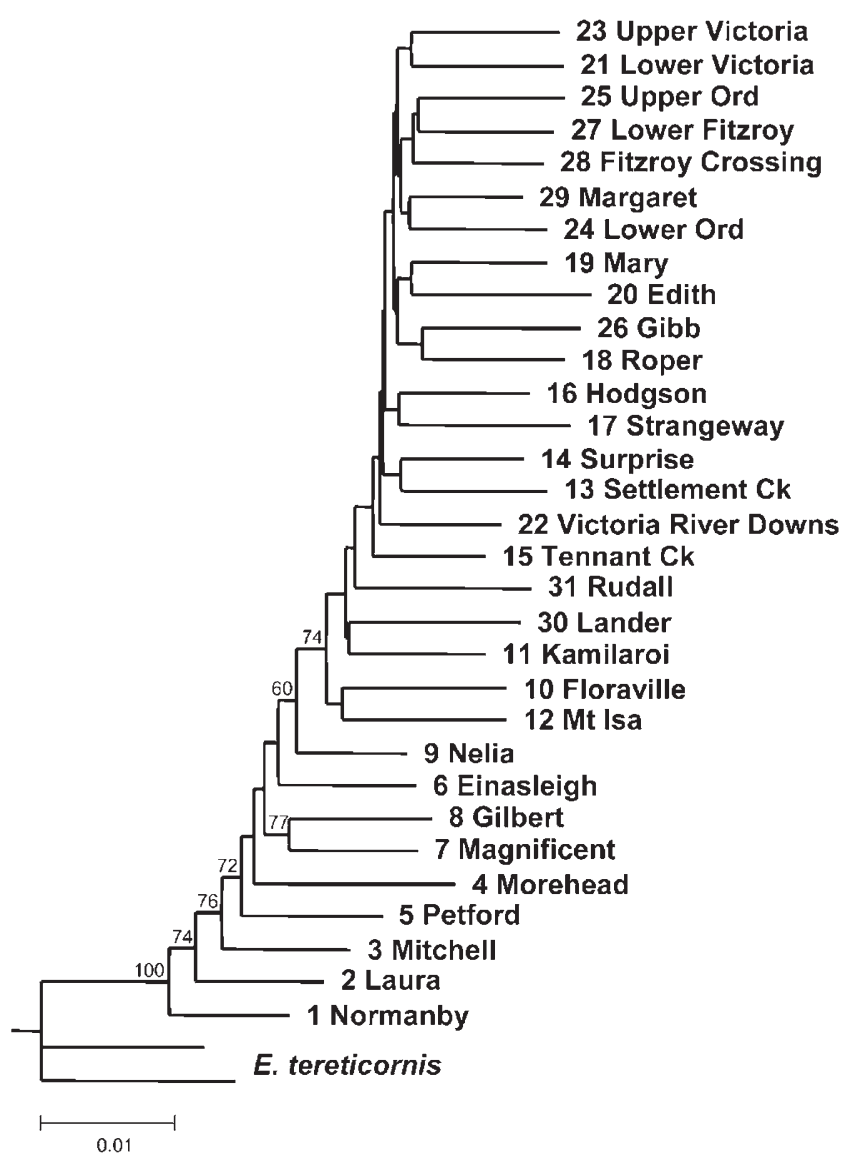

Figure 4 Consensus tree based on restricted maximum likelihood analysis, showing phylogenetic relationships among 31 populations of Eucalyptus camaldulensis, with E. tereticornis as an outgroup. Numbers on the nodes represent the percentage of trees containing the group of populations above the node, out of 500 bootstrapped trees. (Only bootstrap values $>50 \%$ are shown.) Scale represents expected accumulated variance based on Cavalli-Sforza distances.

regions. Differences between the peak flowering times of June-July in the eastern region and October-November in the western region, would severely limit gene flow. Historical processes may also be involved. In the Late Tertiary and Early Pleistocene eastern and central Australian populations belonged to the same drainage division. Relative up-tilting at the margin of the Barkly Tableland and establishment of internal drainage north of the MacDonnell Ranges (Mabbutt, 1962) may have isolated these populations from the Gulf of Carpentaria system and formed a barrier to gene flow between eastern and western regions. This is consistent with reports of genetic divergence in several other species with distributions extending from Queensland to Northern Territory. For example, allozyme surveys revealed populations of Acacia auriculiformis from Northern Territory were genetically distinct from Queensland populations and had lower genetic diversity (Wickneswari and Norwati, 1993). Similarly, a population of Casuarina cunninghamiana from Northern Territory was genetically distinct from populations in Queensland and New South Wales (Moran et al, 1989). In common with E. camaldulensis, these species are confined to locations where their roots can exploit a supply of permanent or semi-permanent ground or surface water.
Divergence between eastern and western E. camaldulensis populations has also been reported in growth rates, phytochemical traits and morphology. In provenance trials of E. camaldulensis in Thailand, mean volume per tree was, on average, 25\% higher for Queensland populations than sources from Northern Territory and Western Australia (Pinyopusarerk et al, 1996). Banks and Hillis (1969) divided E. camaldulensis populations into phytochemical provinces which corresponded with the major river drainage systems and with groupings based on morphological characters. However, the correlation between phytochemical profile and geographic region was poor for populations in inland Western Australia, Northern Territory and the Lake Eyre Basin. Similarly, Grunwald and Karschon (1983) were able to differentiate populations from the Timor Sea drainage division (the north-west of Western Australia and Northern Territory) from those in the Gulf of Carpentaria drainage division (northern Queensland and the north-east of Northern Territory) in factor and cluster analyses based on nine morphometric traits. Populations in these drainage divisions had exoreic drainage. Again, populations with endoreic drainage did not follow this trend. Populations around Alice Springs had closer affinities with the Gulf of Carpentaria drainage division. This is consistent with the RFLP data, where the Rudall and Lander River populations, with endoreic drainage, had closer affinities with the eastern populations than the west (Figure 2).

\section{Hybridisation between var. obtusa and E. tereticornis}

The low genetic distances separating subsp. simulata, Petford and Morehead populations and E. tereticornis supports morphological evidence of hybridisation in regions where the species are parapatric. Subspecies simulata has morphological characters of E. camaldulensis (juvenile leaves and brown seeds) and E. tereticornis (habitat, hornshaped operculum, single seed coat). However, populations such as Morehead and Petford include individuals with a combination of morphological characters that cannot easily be assigned to either taxon.

The high level of variation in the Petford population, together with the high number of private and rare alleles is consistent with speculation that the population is in a zone of introgression (Doran and Burgess, 1993; Brooker and Kleinig, 1994). The Petford and subsp. simulata populations had the same common allele at three loci as E. tereticornis, which differed from all other populations sampled. The Petford population is located on a southern tributary of the Walsh River which, like many upper tributaries of rivers in this region, extends east into the forest habitat of E. tereticornis. Based on bud shape, Doran and Burgess (1993) presented morphological evidence of a complex introgression pattern between var. obtusa and E. tereticornis in the Petford region. When seed coat anatomy and seedling morphology is considered the pattern becomes even more complex. The presence of individuals producing single-coated, black seeds (typical of E. tereticornis) and other individuals producing brown, double-coated seeds (typical of var. obtusa) suggests that the Petford population includes E. camaldulensis $\times$ E. tereticornis hybrids rather than subsp. simulata. Interestingly, the nearest known population of subsp. simulata to the Petford population is about $30 \mathrm{~km}$ away. Eucalyptus tereticornis and var. obtusa flower synchronously and viable seed has been produced following cross-pollination 
(Doran and Burgess, 1993). Based on genetic distances from the limited number of individuals of E. tereticornis examined, subsp. simulata populations have closer affinities to E. tereticornis than Petford (see Figure 3).

Rare individuals having the morphological characters of subsp. simulata have also been documented in the Morehead population (4) (DA Kleinig, personal communication). This population had the same common alleles at two loci as subsp. simulata, Petford and E. tereticornis, providing some evidence of hybridisation. It was, however, genetically distinct (Figure 2), having a different common allele to all other populations at one locus. The difference may reflect the location of Morehead at the northeastern limit of the distribution of var. obtusa. The Morehead River is the only river system flowing east into the Pacific Ocean; all other Queensland populations are located on rivers flowing into the Gulf of Carpentaria.

\section{Implications for breeding programmes}

The patterns of genetic variation in northern populations of E. camaldulensis revealed by RFLP analysis will assist in more clearly defining genetic boundaries for tree breeding programmes. Differentiation among populations to the east and west of the Leichhardt River did not coincide with the current boundaries between drainage divisions. While the majority of variation was detected within populations, the significant differences among populations, together with the geographic trends in allele frequencies, emphasise the importance of the concept of geographic provenance for breeding and/or conservation programmes. In general, geographic distance provides a reasonable indicator of the degree of genetic divergence in northern populations of E. camaldulensis. Superimposed on this trend is the correlation of allele frequencies with climatic parameters (mean annual rainfall and temperature) supporting the need for climatic profiling of provenances for domestication programmes (Booth, 1996).

Greater differentiation among eastern populations indicates the need for greater sampling effort in this region for breeding programmes than among the western populations. In addition, the morphological and genetic affinities of the easternmost populations of var. obtusa with E. tereticornis, in particular Petford, Morehead and subsp. simulata populations, should be considered when designing sampling or breeding programmes. RFLP data for populations of E. tereticornis throughout its northeastern range would assist in more clearly delineating the boundaries between these taxa.

\section{Acknowledgements}

Financial support for this research was provided by the Australian Tree Seed Centre (ATSC), CSIRO Forestry and Forest Products. Many thanks to Ian Brooker, Andrew Slee, John Connors (Centre for Biodiversity, CSIRO Plant Industry), Craig Gardiner, Jock Morse and Sarah Whitfeld (ATSC) for collection of leaf samples and field data; Guiseppina Morosin for technical assistance; Tom Jovanovic for BIOCLIM analyses; Jeff Glaubitz, Harry Wu and Colin Matheson for assistance with statistical analyses. Thanks also to Andrew Young and Charlie Bell for constructive comments on the manuscript.

\section{References}

Aradhya KM, Phillips VD (1995). Lack of association between allozyme heterozygosity and juvenile traits in Eucalyptus. New Forests 9: 97-110.

Aravanopoulos FA (2000). Absence of association between heterozygosity and biomass production in Salix exigua Nutt. Theor Appl Genet 100: 1203-1208.

Banks JCG (1990). Flowering patterns in Eucalyptus camaldulensis Dehnh. Proceedings of the Eucalypt Anniversary Symposium, Zanjiang, China, 22-30 November, (1990).

Banks JCG, Hillis WE (1969). The characterization of populations of Eucalyptus camaldulensis by chemical features. Aust J Bot 17: 133-146.

Blakely WF (1965) A Key to the Eucalypts. Forestry and Timber Bureau, Canberra.

Boland DJ, Brooker MIH, Turnbull JW (1980). Eucalyptus Seed. CSIRO: Australia.

Booth TH (ed) (1996). Matching Trees and Sites. ACIAR Proceedings No. 63, ACIAR, Canberra. 128 pp.

Brooker MIH, Kleinig DA (1994). Field Guide to Eucalypts. Vol. 3, Northern Australia. Inkata Press: Sydney.

Brooker MIH, Slee AV (2000). Studies in the red gums of southeastern Australia with particular emphasis on Eucalyptus subser. Erythroxyla Aust Forestry 63: 86-106.

Butcher PA, Moran GF, Perkins HD (1996). Genetic resources and domestication of Acacia mangium. In: Dieters MJ, Matheson AC, Nikles DG, Harwood CE, Walker SM (eds) Tree Improvement for Sustainable Tropical Forestry. Proceedings QFRI-IUFRO Conference, Caloundra, Queensland, 27 Oct to 1 Nov 1996, Queensland Forestry Research Institute, Gympie. pp 467-471.

Byrne M (1999). High genetic identities between three oil mallee taxa, Eucalyptus kochii ssp. kochii, ssp. plenissima and E. horistes, based on nuclear RFLP analysis. Heredity 82: 205-211.

Byrne M, Moran GF, Tibbetts WN (1993). Restriction map and maternal inheritance of chloroplast DNA in Eucalyptus nitens. J Hered 84: 218-220.

Byrne M, Murrell JC, Allen B, Moran GF (1995). An integrated genetic linkage map for eucalypts using RFLP, RAPD and isozyme markers. Theor Appl Genet 91: 869-875.

Byrne M, Parrish TL, Moran GF (1998). Nuclear RFLP diversity in Eucalyptus nitens. Heredity 81: 225-233.

Cavalli-Sforza LL (1966). Population structure and human evolution. Proc Roy Soc B 164: 362-379.

Chakraborty R, Fuerst PA, Nei M (1980). Statistical studies on protein polymorphism in natural populations. III. Distribution of allele frequencies and the number of alleles per locus. Genetics 94: 1039-1063.

Doran JC, Burgess IP (1993). Variation in floral bud morphology in the intergrading zones of Eucalyptus camaldulensis and E. tereticornis in Northern Queensland. Comm For Rev 72: 198202.

Eldridge K, Davidson J, Harwood C, Van Wyk G (1993). Eucalypt Domestication and Breeding. Clarendon Press: Oxford.

Feinberg AP, Vogelstein B (1983). A technique for radiolabelling DNA restriction endonuclease fragments to high specific activity. Anal Biochem 132: 6-13.

Felsenstein J (1993). PHYLIP (Phylogeny Inference Package) Version 3.5c. Distributed by the author. Department of Genetics, University of Washington, Seattle.

Franklin DC, Noske RA (2000). Nectar sources used by birds in monsoonal north-western Australia: a regional survey. Aust J Bot 48: 461-474.

Gibson A, Bachelard EP, Hubick KT (1995). Relationship between climate and provenance variation in Eucalyptus camaldulensis Dehnh. Aust J Plant Physiol 22: 453-460.

Glaubitz JC, Strk J, Moran GF (1999). Genetic impact of different silvicultural practices in native eucalypt forests. In: Matyas C (ed) Forest Genetics and Sustainability, Kluwer Academic Publishers, Dordrecht. pp 183-195.

Goudet J (2000). FSTAT, a programme to estimate and test gene 
diversities and fixation indices (Version 2.9.1). Available from http://www.unil.ch/izea/softwares/fstat.html.

Grunwald C, Karschon R (1977). Clinal variation in leaf dry matter content in Eucalyptus camaldulensis Dehnh. and its relation to frost resistance. La-Yaaran 27: 48-51.

Grunwald C, Karschon R (1983). Variation of Eucalyptus camaldulensis from north Australia grown in Israel. Silv Genet 32: 165-172.

Lewis PO, Zaykin D (1999). Genetic Data Analysis: Computer programme for the analysis of allelic data. Version 1.0 (d13). Free programme distributed from the GDA Home Page at http://alleyn.eeb.uconn.edu/gda/

Liedloff A, Mayes P, Ramsey D (1997). Mantel Nonparametric Test Calculator for Windows. Version 1.21. Queensland University of Technology, School of Natural Resource Sciences: Brisbane.

Mabbutt JA (1962). Geomorphology of the Alice Springs Area. CSIRO Land Resources Series 6: 163-184.

McDonald MW, Bell JC, Butcher PA (1996). Effect of seed collection strategies on capturing genetic diversity in Eucalyptus camaldulensis. In: Olesen K. (ed) Innovations in Tropical Tree Seed Technology, Proceedings of the IUFRO Symposium of Project Group P.2.04.00 'Seed Problems', Arusha, Tanzania, 7-10 September 1995. pp 166-174.

Midgley SJ, Eldridge KG, Doran JC (1989). Genetic resources of Eucalyptus camaldulensis. Comm For Rev 68: 295-308.

Moran GF, Bell JC, Turnbull JW (1989). A cline in genetic diversity in river she-oak Casuarina cunninghamiana. Aust J Bot 37: 169-180.

Nei M (1972). Genetic distance between populations. Amer Nat 106: 283-292.

Nei M (1973). Analysis of gene diversity in subdivided populations. Proc Natl Acad Sci USA 70: 3321-3323.

Nei M (1978). Estimation of average heterozygosity and genetic distance from a small number of individuals. Genetics 89: 583-590.

Otegbeye GO (1985). Provenance productivity in Eucalyptus camaldulensis Dehnh. and its implications to genetic improvement in the Savannah Region of Nigeria. Silv Genet 34: 121-126.

Pinyopusarerk K, Doran JC, Williams ER, Wasuwanich P (1996). Variation in growth of Eucalyptus camaldulensis provenances in Thailand. Forest Ecol Man 87: 63-73.

Pryor LD, Byrne OR (1969). Variation and taxonomy in Eucalyptus camaldulensis. Silv Genet 18: 64-71.

Richards GC (1995). A review of ecological interactions of fruit bats in Australian ecosystems. Symposia Zool Soc London 67: 79-96.

Ritland K (1989). Genetic differentiation, diversity and inbreeding in the mountain monkey flower (Mimulus caespitosus) in the Washington Cascades. Can J Bot 67: 2017-2024.

SAS Institute Inc (1989). SAS/STAT User's Guide, Version 6, Fourth Edition, Vols 1E2, Cary, NC, USA.

Savolainen O, Hedrick P (1995). Heterozygosity and fitness: no association in Scots pine. Genetics 140: 755-766.

Thamarus KA, Groom K, Murrell J, Byrne M, Moran GF (2001). A genetic linkage map for Eucalyptus globulus with candidate loci for wood, fibre and floral traits. Theor Appl Genet 104: 379-387.

Turnbull JW (1973). The ecology and variation of Eucalyptus camaldulensis Dehnh. FAO Forest Gen Res Info 2: 32-42.

Yeh FC, Boyle T (1999). Popgene Version 1.31. Microsoft Window-freeware for population genetic analysis. University of Alberta and CIFOR. Home Page at http://www. ualberta.ca/fyeh/index.htm

Weir BS (1996). Genetic Data Analysis II: Methods for Discrete Population Genetic Data. Sinauer Associates: Sunderland, Massachusetts.

Wickneswari R, Norwati M (1993). Genetic diversity of natural populations of Acacia auriculiformis. Aust J Bot 41: 65-77. 